\title{
CORRELATIVE STUDY OF ECG AND ECHOCARDIOGRAPHIC FINDINGS IN COPD PATIENTS
}

\author{
Anil Kumar Hanumanthaiah ${ }^{1}$
}

${ }^{1}$ Associate Professor, Department of General Medicine, RRMCH, Bangalore.

\section{ABSTRACT}

\section{OBJECTIVES}

Chronic Obstructive Pulmonary Disease (COPD) is one of the commonest causes of mortality and morbidity in our country. The habit of smoking, increasing air pollution and other environmental factors facilitate the occurrence of this condition. COPD causes pulmonary hypertension through several inter-related mechanisms including hypoventilation, hypoxemia from ventilation perfusion mismatch and destruction of perfused surface area. The altered haematological and hemo-rheological factors also contribute to the development of pulmonary hypertension in COPD. Our study aims at correlating ECG and Echocardiographic findings with the severity of COPD.

\section{METHODS}

Our study was conducted at a tertiary hospital in Bangalore. We studied 61 patients, among them 21 were mild COPD, 20 were moderate COPD and 20 patients belonged to severe COPD patients. Patients with COPD as defined by ATS (American Thoracic Society) were studied. The lung function parameters were assessed by Spiroanalyser (Vitalograph). They were categorised into mild, moderate and severe COPD based on the percentage of predicted FEV1. All of them underwent detailed clinical examination, ECG, Echocardiography and routine investigations.

\section{RESULTS}

The mean age of all patients was $61.11 \pm 10.51$ years and majority $85.25 \%$ were males. The most common ECG finding observed in all the groups was 'P' pulmonale [28.57\%, 40\%, 45\% in mild, moderate and severe COPD respectively]. The mean RV area, RA area, RVAWT were $14.26 \pm 4.82 \mathrm{~cm}^{2}, 7.98 \pm 1.97 \mathrm{~cm}^{2}$ and $0.61 \pm 0.18 \mathrm{cms} ; 19.19 \pm 6.02 \mathrm{~cm}^{2}, 10.68 \pm 3.45 \mathrm{~cm}^{2}$ and $0.83 \pm 0.17 \mathrm{cms}$; and $23.43 \pm 5.83 \mathrm{~cm}^{2}, 13.58 \pm 3.18 \mathrm{~cm}^{2}$ and $0.91 \pm 0.18 \mathrm{cms}$ in mild, moderate and severe COPD patients respectively.

\section{KEYWORDS}

COPD, ECG, Echocardiography, PFT.

HOW TO CITE THIS ARTICLE: Hanumanthaiah AK. Correlative study of ECG and Echocardiographic findings in COPD patients. J. Evolution Med. Dent. Sci. 2016;5(18):897-901, DOI: 10.14260/jemds/2016/207

\section{INTRODUCTION}

Chronic Obstructive Pulmonary Disease is one of the most common causes of mortality and morbidity in our country. The habit of smoking, increasing air pollution and other environmental factors facilitate the occurrence of the condition. Chronic obstructive lung disease is defined as a condition, in which there is a chronic obstruction of air flow. ${ }^{1}$ Although, the degree of obstruction may be less when the patient is free from respiratory infection and may improve somewhat with bronchodilator drugs, significant obstruction is always present. Chronic obstructive pulmonary disease includes chronic bronchitis and emphysema. Chronic bronchitis is a condition associated with excessive trachea bronchial mucus production sufficient to cause cough with expectoration for at least 3 months of the year for more than two consecutive years. ${ }^{2}$ Emphysema is characterized by abnormal permanent dilatation of air spaces distal to the terminal bronchioles, accompanied by destruction of their walls and without obvious fibrosis. Chronic Obstructive lung disease causes cor pulmonale through several inter-related mechanisms including hypoventilation, hypoxemia from ventilation perfusion mismatch, decreased surface area and

Financial or Other, Competing Interest: None.

Submission 17-01-2016, Peer Review 13-02-2016,

Acceptance 18-02-2016, Published 02-03-2016.

Corresponding Author:

Dr. Anil Kumar Hanumanthaiah,

\# 306, $6^{\text {th }}$ Main, $1^{\text {st }}$ Cross, REMCO Layout,

Vijaynagar $2^{\text {nd }}$ stage,

Bangalore-560104.

E-mail: dranilkh1@gmail.com

DOI: $10.14260 /$ jemds/2016/207 polycythemia. Chronic cor pulmonale is defined as the "Hypertrophy of right ventricle from diseases affecting the function and/or the structure of the lung, except when these pulmonary alterations are the result of diseases that primarily affect the left side of the heart or the congenital heart disease." Cor pulmonale is an important cause of mortality in patients with COPD.(3) ECG and Echocardiography are two important investigations, which aid in the diagnosis of cor pulmonale. ECG is relatively insensitive in demonstrating right heart enlargement because the enlarged lungs are poor electrical conductors and the inspiratory position of the chest is associated with a vertically positioned heart.(4) Echocardiography with its unique inherent qualities of safety, easy operability of the machine, adequate reproducibility and accuracy appears well suited to fill the void. Moreover, echocardiography can aid in the early detection of cor pulmonale.

\section{REVIEW OF LITERATURE}

In patients with COPD involvement of right heart is well documented. The pulmonary cardiovascular complications in this disease is the development of pulmonary arterial hypertension. Hypoxic vasoconstriction, acidosis, reduction in pulmonary vascular bed because of lung destruction or intercurrent pulmonary thromboembolism as well as polycythemia have been shown to contribute to the development and maintenance of pulmonary hypertension. Right ventricular hypertrophy develops in response to this increased after load and eventually right sided congestive heart failure ensues. 5,6 
Evaluation of right ventricular performance in COPD have been done by both invasive and non-invasive techniques.

In patient with COPD, the presence of clear cut electrocardiographic features of right ventricular hypertrophy or right ventricular dilatation establishes the diagnosis of cor pulmonale frequently; however, the electrocardiographic changes that occur are usually not typical of right ventricular hypertrophy or right ventricular dilatation, but are only suggestive and reflect the presence of COPD.

The study of right ventricle by echocardiography is a useful technique in the non-invasive assessment of pulmonary hypertension on right heart in COPD. The echocardiographic criteria for the diagnosis of right ventricular hypertrophy correlating them with ECG and necropsy findings were published by Prakash and O'Meara in 1979.7 In 1981, Baker et al. conducted their study on the echocardiographic detection of right ventricular hypertrophy by relating right ventricular internal diameter and right ventricular free wall thickness to anatomic right ventricular mass. ${ }^{8}$ They concluded that $\mathrm{M}$ mode echocardiogram was a highly specific tool for predicting the presence of an increased right ventricular mass.

Bertoli et al. studied right heart impairment in COPD together with hemodynamics, using M-mode echocardiography. They showed that Right Ventricular Index (RVI) or the end-diastolic right ventricular diameter and the Right Ventricular Anterior Wall Thickness (RVAWT) were increased in most patients of the study group. There was good correlation between echocardiographic parameters, hemodynamics and pulmonary function parameters. ${ }^{9}$ the authors concluded that echocardiography may be a useful technique in the non-invasive assessment of pulmonary hypertension on right heart in COPD.

Kushner et al. studied the role of cross-sectional echocardiography utilising the four chambers apical view to evaluate right atrial dimensions as a mean of detecting abnormal right heart hemodynamics. And a conclusion was reached that apical echocardiography may be more sensitive than M-mode echocardiography in detecting in specific early right heart involvement in specific cardiac conditions. ${ }^{10}$

\section{MATERIALS AND METHODS}

\section{Inclusion Criteria}

Adult males and females ages more than 18 years with a known history of chronic obstructive pulmonary airway disease were selected at random from the outpatient department, medical wards of a tertiary hospital, Bangalore for the present study.

The diagnosis of chronic obstructive pulmonary disease was made by symptoms in the history and confirmed by physical examination, radiographic examination and lung function tests for airway obstruction by spiroanalyser (Vitalograph).

The patients who were diagnosed as having chronic obstructive pulmonary airway disease were further divided into 3 groups.
Group I: 21 patients were selected who fulfilled the above criteria and belong to mild COPD based on percentage of predicted FEV1.

Group II: 20 patients were selected who fulfilled the above criteria and belong to moderate COPD based on percentage of predicted FEV1.

Group III: 20 patients were selected who fulfilled the above criteria and belong to severe COPD based on percentage FEV1.

\section{Exclusion Criteria}

1. Cases excluded from the present study are primary diagnosis of bronchial asthma, known sleep apnea, lung cancer, known left ventricular dysfunction. Other debilitating cancers, poorly controlled hypertension, significant valvular disease and known coronary artery diseases (Angina, ischaemic changes in resting ECG or documented history of myocardial infarction).

2. Very poor echogenic subjects in whom meaningful echocardiographic examination could not be performed were also excluded from the present study.

Cases with non-visualisation or poor visualisation on only one or few parameters being studied in the presence of recordable readings of the other parameters, however, were included.

\section{PROCEDURE}

After recruitment for the study and doing routine investigation with special reference to $\mathrm{Hb} \%$ and PCV (as per proforma) the patients were subjected to the following examination.

1. Physical examination: Thorough physical examination was done to determine any direct or indirect evidence of cor pulmonale.

2. Radiographic examination: Chest X-ray postero-anterior view was obtained to detect right heart enlargement and/or pulmonary artery dilatation.

\section{Electrocardiographic Assessment}

A standard 12-lead electrocardiography was obtained for each using a portable ECG machine. The following criteria was used to detect right ventricular hypertrophy. ${ }^{11}$

a. P-pulmonale pattern ( $\mathrm{P}$ wave $>2.5 \mathrm{~mm}$ ) in leads II, III, avF.

b. Right axis deviation of QRS complex.

c. $\mathrm{R} / \mathrm{S}$ amplitude ratio in $\mathrm{V} 6$ is less than 1.

d. R/S amplitude ratio in V1 more than 1.

e. Clockwise rotation of the electrical axis.

f. Right bundle branch block.

g. $\mathrm{S} 1, \mathrm{Q} 3$ or $\mathrm{S} 1, \mathrm{~S} 2, \mathrm{~S} 3$ patterns.

\section{STATISTICAL SOFTWARE}

The statistical software namely SPSS 11.0 and Systat 8.0 were used. If $\mathrm{P}<0.05$ statistical significance at $5 \%$ and $\mathrm{P}<0.01$ statistical significance at $1 \%$. 


\begin{tabular}{|c|c|c|c|c|c|c|c|c|}
\hline Age in Years & Mild COPD (n=21) & & Moderate COPD (n=20) & & Severe COPD $(n=20)$ & & Total & \\
\hline & No. & $\%$ & No. & $\%$ & No. & $\%$ & No. & $\%$ \\
\hline$<40$ & 1 & 4.76 & - & - & 1 & 5 & 2 & 3.3 \\
\hline $41-50$ & 2 & 9.52 & 1 & 5 & 3 & 15 & 6 & 9.84 \\
\hline $51-60$ & 9 & 42.86 & 6 & 30 & 10 & 50 & 25 & 40.98 \\
\hline $61-70$ & 5 & 23.81 & 8 & 40 & 5 & 25 & 18 & 29.51 \\
\hline $71-80$ & 4 & 19.05 & 3 & 15 & 1 & 5 & 8 & 13.11 \\
\hline$>80$ & - & - & 2 & 10 & - & - & 2 & 3.27 \\
\hline \multicolumn{9}{|c|}{ Table 1(a): Age Distribution } \\
\hline
\end{tabular}

\begin{tabular}{|c|c|c|c|c|}
\hline Sex & Mild COPD (n=21) & Moderate COPD (n=20) & Severe COPD (n=20) & Total (n= 61) \\
\hline Male & $19(90.48 \%)$ & $16(80 \%)$ & $17(85 \%)$ & $52(85.25 \%)$ \\
\hline Female & $2(9.52 \%)$ & $4(20 \%)$ & $3(15 \%)$ & $9(14.75 \%)$ \\
\hline \multicolumn{4}{|r|}{ Table 1 (b): Sex Distribution } \\
\hline
\end{tabular}

\begin{tabular}{|c|c|c|}
\hline Duration of Smoking & Number & Percentage \\
\hline$>25$ years & 12 & 19.67 \\
\hline $16-25$ years & 17 & 27.87 \\
\hline 6-15 years & 18 & 29.51 \\
\hline$<6$ years & 3 & 4.92 \\
\hline No smoking & 11 & 18.03 \\
\hline \multicolumn{2}{|c|}{ Table 2: Smoking Habits } \\
\hline
\end{tabular}

\begin{tabular}{|c|c|c|c|c|}
\hline Signs & Mild COPD (n=21) & Moderate COPD (n=20) & Severe COPD (n= 20) & Total (n=61) \\
\hline Tachypnea & $10(47.62 \%)$ & $18(90 \%)$ & $20(100 \%)$ & $48(78.69 \%)$ \\
\hline Cyanosis & - & $6(30 \%)$ & $8(40 \%)$ & $14(22.95 \%)$ \\
\hline Clubbing & $8(38.09 \%)$ & $10(50 \%)$ & $12(60 \%)$ & $14(22.95 \%)$ \\
\hline Pedal edema & - & $4(20 \%)$ & $13(65 \%)$ & $17(27.88 \%)$ \\
\hline Emphysematous chest & $7(33.33 \%)$ & $7(35 \%)$ & $6(30 \%)$ & $20(32.79 \%)$ \\
\hline \multicolumn{5}{|r|}{ Table 3: Presentation of signs in COPD patients } \\
\hline
\end{tabular}

\begin{tabular}{|c|c|c|c|c|}
\hline Systemic Examination & Mild COPD (n=21) & $\begin{array}{c}\text { Moderate COPD } \\
(\mathbf{n = 2 0 )}\end{array}$ & $\begin{array}{c}\text { Severe COPD } \\
(\mathbf{n = 2 0})\end{array}$ & Total (n=61) \\
\hline 个JVP & $2(9.52 \%)$ & $5(25 \%)$ & $12(60 \%)$ & $19(31.15 \%)$ \\
\hline Resonance & $7(33.33 \%)$ & $5(25 \%)$ & $7(35 \%)$ & $19(31.15 \%)$ \\
\hline Rhonchi & $8(38.09 \%)$ & $11(55 \%)$ & $7(35 \%)$ & $26(42.62 \%)$ \\
\hline Crepitation & $5(23.81 \%)$ & $12(60 \%)$ & $17(85 \%)$ & $34(55.73 \%)$ \\
\hline $\begin{array}{c}\text { Epigastric + Parasternal } \\
\text { pulsation }\end{array}$ & - & $3(15 \%)$ & $8(40 \%)$ & $11(18.03 \%)$ \\
\hline Loud P2 & $3(14.29 \%)$ & $5(25 \%)$ & $10(50 \%)$ & $18(29.51 \%)$ \\
\hline S3 & - & - & $3(15 \%)$ & $3(4.91 \%)$ \\
\hline Pansystolic murmur & - & $1(5 \%)$ & $4(20 \%)$ & $5(8.19 \%)$ \\
\hline Hepatomegaly & $-\quad 4(20 \%)$ & $10(50 \%)$ & $14(22.95 \%)$ \\
\hline
\end{tabular}

\begin{tabular}{|c|c|c|c|c|}
\hline Chest X-Ray Findings & $\begin{array}{c}\text { Mild COPD } \\
(\mathbf{n = 2 1})\end{array}$ & $\begin{array}{c}\text { Moderate COPD } \\
(\mathbf{n = 2 0})\end{array}$ & $\begin{array}{c}\text { Severe COPD } \\
(\mathbf{n = 2 0})\end{array}$ & Total (n=61) \\
\hline Emphysema & $6(28.57 \%)$ & $9(45 \%)$ & $9(45 \%)$ & $24(39.34 \%)$ \\
\hline Cardiomegaly & - & $2(10 \%)$ & $9(45 \%)$ & $11(18.03 \%)$ \\
\hline $\begin{array}{c}\text { Prominent Pulmonary } \\
\text { Conus }\end{array}$ & $1(4.76 \%)$ & $2(10 \%)$ & $6(30 \%)$ & $9(9.89 \%)$ \\
\hline \multicolumn{4}{|c|}{ Table 5: Radiological Parameters } \\
\hline
\end{tabular}

\begin{tabular}{|c|c|c|c|}
\hline COPD & FEV1 (Mean \pm SD) & FVC (Mean \pm SD) & FEV1\% (Mean \pm SD) \\
\hline Mild & $1.61 \pm 0.33$ & $2.45 \pm 0.45$ & $65.59 \pm 3.39$ \\
\hline Moderate & $1.01 \pm 0.29$ & $2.08 \pm 0.43$ & $49.69 \pm 5.84$ \\
\hline Severe & $0.61 \pm 0.23$ & $2.18 \pm 0.53$ & $30.11 \pm 6.72$ \\
\hline Total & $\mathbf{1 . 0 9 \pm 0 . 5 0}$ & $\mathbf{2 . 1 8} \pm 0.53$ & $\mathbf{4 8 . 7 4 \pm 1 5 . 6 3}$ \\
\hline \multicolumn{2}{|r|}{ Table 6: Pulmonary Function Tests } \\
\hline
\end{tabular}




\begin{tabular}{|c|c|c|c|c|}
\hline ECG Findings & Mild COPD (n=21) & $\begin{array}{c}\text { Moderate COPD } \\
(\mathbf{n = 2 0})\end{array}$ & $\begin{array}{c}\text { Severe COPD } \\
(\mathbf{n = 2 0})\end{array}$ & $\begin{array}{c}\text { Total } \\
(\mathbf{n = 6 1})\end{array}$ \\
\hline 'P' pulmonale & $6(28.57 \%)$ & $8(40 \%)$ & $9(45 \%)$ & $23(37.7 \%)$ \\
\hline R/S in V1>1 & $1(4.76 \%)$ & $1(5 \%)$ & $3(15 \%)$ & $5(8.19 \%)$ \\
\hline R/S in V6<1 & $2(9.52 \%)$ & $5(25 \%)$ & $8(40 \%)$ & $15(24.59 \%)$ \\
\hline Right axis deviation & $1(4.76 \%)$ & $4(20 \%)$ & $7(35 \%)$ & $12(19.67 \%)$ \\
\hline RBBB & $1(4.76 \%)$ & $2(10 \%)$ & $3(15 \%)$ & $6(9.84 \%)$ \\
\hline S1,S2,S3 or S1Q3 & - & - & - & - \\
\hline \multicolumn{4}{|r|}{ Table 7: ECG Parameters } \\
\hline
\end{tabular}

\begin{tabular}{|c|c|c|c|}
\hline COPD & $\begin{array}{c}\text { RV Area (cm } \\
\text { Mean } \pm \text { SD }\end{array}$ & $\begin{array}{c}\text { RA Area (cm } \\
\text { Mean } \pm \text { SD }\end{array}$ & $\begin{array}{c}\text { RVAWT (cms) } \\
\text { Mean } \pm \text { SD }\end{array}$ \\
\hline Mild & $14.26 \pm 4.82$ & $7.98 \pm 1.97$ & $0.61 \pm 0.18$ \\
\hline Moderate & $19.19 \pm 6.02$ & $10.68 \pm 3.45$ & $0.83 \pm 0.17$ \\
\hline Severe & $23.43 \pm 5.83$ & $13.58 \pm 3.18$ & $0.91 \pm 0.18$ \\
\hline Total & $\mathbf{1 8 . 8 0 \pm 6 . 6 6}$ & $\mathbf{1 0 . 6 5} \pm 3.68$ & $\mathbf{0 . 7 8} \pm \mathbf{0 . 2 1}$ \\
\hline \multicolumn{2}{|r|}{ Table 8: Echocardiographic Findings } \\
\hline
\end{tabular}

\section{RESULTS}

The present study included 61 patients with COPD, attending medical outpatient department or admitted to the various medical wards/ICU tertiary care hospital, Bengaluru.

The age of the patients ranged between $39 \mathrm{yrs}$. to 84 yrs., of which 52 people were male and 9 were female. The age distribution in different groups were mild COPD group $(66+11.29$ yrs.), moderate COPD group $(65.60+9.90$ yrs.) and in severe COPD group $(57.80+9.08$ yrs.) respectively. All male patients except 2 had a history of smoking for 5 yrs. or more.

In 9 female and 2 male patients who did not smoke, no definite cause could be established and hence environmental factors for example air pollution and passive smoking was considered the possible etiology for COPD in them.

The favoured mode of smoking was cigarettes. The most common clinical sign was tachypnea followed by clubbing and emphysematous chest respectively. JVP was elevated significantly in Severe COPD (60\%) compared to Moderate (25\%) and Mild (9.52\%) groups. Loud P2 was found most commonly in Severe COPD (50\%) compared to Moderate (25\%) and Mild (14.29\%) groups. The most common chest Xray finding was emphysema. The most consistent ECG findings was ' $\mathrm{P}$ ' pulmonale followed by $\mathrm{R} / \mathrm{S}$ in $\mathrm{V} 6<1$.

Echocardiographic study was carried out in M-mode and 2-D Echocardiography. In our study, the minimum and maximum values of RV area ranged from $9.4-25.5 \mathrm{~cm}^{2}$ with a mean of $14.26 \pm 4.82 \mathrm{~cm}^{2}, 11.6-34.1 \mathrm{~cm}^{2}$ with a mean of $19.19 \pm 6.02 \mathrm{~cm}^{2}$ and $16.1-36.5 \mathrm{~cm}^{2}$ with a mean of $23.43 \pm 5.83 \mathrm{~cm}^{2}$ in mild, moderate and severe COPD respectively. RVAWT values ranged from $0.3-1.0 \mathrm{~cm}$ with the mean of $0.61 \pm 0.18,0.6-1.1 \mathrm{cms}$ with the mean of $0.83 \pm 0.17$ and 0.6-1.2 with the mean of $0.91 \pm 0.18$ in Mild, Moderate and Severe COPD patients respectively.

\section{DISCUSSION}

The present cross-sectional study was undertaken to investigate the pattern and magnitude of clinical parameters as well as lab parameters mainly ECG and Echocardiography and to investigate the relationship between the severity of disease with ECG and Echocardiography. In this study, 82\% of patients were smokers and the favoured mode of smoking was cigarettes. Studies on western population had shown that in about $80 \%$ of patients smoking was the main etiological factor leading on to COPD. About $60 \%$ of patients with severe obstruction had raised JVP, which is statistically significant $(\mathrm{P}=0.001)$ and the Odds ratio $(\mathrm{OR})=7.28$, indicating that the patients with severe obstruction are 7.28 times more likely to have right ventricular dysfunction.

In our study, 59\% of patients showed ECG changes suggestive of involvement of right side of the heart. The most common abnormality observed was ' $\mathrm{P}$ ' pulmonale $(37.7 \%)$ and it was more commonly seen in severe COPD patients, although not statistically significant. In a study by Mishra et al. ' $\mathrm{P}$ ' pulmonale was found in $34.4 \%$ of patients. ${ }^{12}$ In another study by Silver et al., it was found to be $46 \% .^{13}$ In our study, the minimum and maximum values of RV area ranged from $9.4-25.5 \mathrm{~cm}^{2}$ with a mean of $14.26 \pm 4.82 \mathrm{~cm}^{2}, 11.6-34.1 \mathrm{~cm}^{2}$ with a mean of $19.19 \pm 6.02 \mathrm{~cm}^{2}$ and $16.1-36.5 \mathrm{~cm}^{2}$ with a mean of $23.43 \pm 5.83 \mathrm{~cm}^{2}$ in Mild, Moderate and Severe COPD respectively. The mean for right ventricular area in Severe COPD patients was significantly more than that in mild and moderate group $(\mathrm{p}<0.001)$. The mean for right atrial area in Severe COPD patients was $13.58 \pm 3.18 \mathrm{~cm}^{2}$ and that of mild and moderate group were $7.98 \pm 1.97 \mathrm{~cm}^{2}$ and $10.68 \pm 3.45 \mathrm{~cm}^{2}$ respectively. The difference between the severe and the other two groups were statistically significant $(\mathrm{p}<0.001)$.

The values of RVAWT in severe COPD patients was $0.91 \pm 0.18 \mathrm{cms}$ and that of mild and moderate group were $0.61 \pm 0.18$ and $0.83 \pm 0.17$ respectively and the difference between the Severe and the other two groups were statistically significant $(\mathrm{p}<0.001)$. In a study by Cacho, et al. the mean RV area was found to be $13.02 \pm 3.64 \mathrm{~cm}^{2}$ and RA area was found to be $8.81 \pm 2.79 \mathrm{~cm}^{2}$ consistent with our findings. ${ }^{14}$

In a study by Bertoli et al. and Oswald et al., the RVAWT was found to be $0.54 \pm 0.14 \mathrm{cms}$ and $0.61 \pm 0.12 \mathrm{cms}$ respectively, which was very much similar to our findings. ${ }^{15,16}$ The minor differences could be due to the categorisation of patients into mild, moderate and severe in our study. 
In this study, we also observed that even some of the patients with mild COPD had already tend to develop features of pulmonary hypertension as evidenced by ECG and Echocardiographic parameters. It may have to be confirmed by large population based studies as the number of patients with mild COPD included in our study is less. Nevertheless, preventive measures like smoking cessation and management of COPD at earlier stage itself can retard the progression of pulmonary hypertension.

\section{CONCLUSION}

In our study, it was observed that the echocardiographic features suggestive of cor pulmonale was significantly more pronounced in patients with severe COPD as compared to mild and moderate COPD groups. The feature of cor pulmonale tend to develop very early in the clinical course of COPD and Echocardiography is a simple bedside tool available to assess the presence of cor pulmonale. However, large population based studies are required to confirm the findings.

\section{REFERENCES}

1. Official statement of American Thoracic Society Standards for the diagnosis and care of patients with chronic obstructive pulmonary disease and asthma. 1987 Am Rev Respir Dis 136;225-244.

2. Medical Research Council. "Definition and classification of chronic bronchitis for clinical and epidemiological purpose." Lancet 1965;1:775.

3. Renzetti AD, McElement JH, Litt BD. "The veteran cooperative study of pulmonary function-III. Mortality in relation to respiratory function in chronic obstructive pulmonary disease." Am J Med 1966;41:115.

4. Eugene Braunwald. Harrison's principles of Internal Medicine, $16^{\text {th }}$ ed. McGraw-Hill Inc 2005;1377. Pp

5. Mathay RA, Berger HJ. "Cardiovascular function in cor pulmonale.” Clinic Chest Med 1983;4:269.
6. Weitzenblum E, Hirth C, Ducolene A. "Prognostic value of pulmonary artery pressure in COPD." Chest 1979;75:656.

7. Prakash R, O’Meara A. 1979. "Echocardiographic criteria for the diagnosis of right ventricular hypertrophy. Correlation with ECG and necropsy in 244 patients." Circulation 60 (Suppl II):25.

8. Baker BJ, et al. 1983. "Echocardiographic detection of right ventricular hypertrophy." Am Heart J 105:611.

9. Bertoli L, et al. "Value of two dimensional echocardiography in the identification of pulmonary hypertension in chronic obstructive lung disease." Respiration 1989;55:193.

10. Kushner FG, Lam W, Morganroth J. "Apex sector echocardiography in evaluation of right atrium in patients with mitral stenosis and atrial septal defect." Am J Cardiol 1978;42:733.

11. Wiedemann HP, Matthay RA. Cor pulmonale in heart disease by Braunwald, $5^{\text {th }}$ Edition, Table 47.2.

12. Mishra DN, Mittal HS. "Electrocardiographic changes in cor pulmonale.” The Clinician, 1976; vol 40.

13. Silver MM and Calatayud JB. Evaluation of QRS criteria in patients with COPD. Chest 1971;69:153.

14. Cacho A, et al. "Usefulness of two dimensional echocardiography in diagnosing right ventricular hypertrophy." Chest 1988;84:154.

15. Oswald Mammoser M, et al. "Non-invasive diagnosis of pulmonary hypertension in chronic obstructive pulmonary disease. Comparison of ECG, radiological measurements. Echocardiology and myocardial scintigraphy." Eur J Respir Dis 1987;71:419.

16. Putnik M, et al. 1998. "Electrocardiography and echocardiography in the diagnosis of chronic cor pulmonale." Med Pregl 51:528-531. 